\title{
REVIEW ON ETHNOBOTANY AND PHYTOPHARMACOLOGY OF CORDIA DICHOTOMA
}

\author{
*Nazim Hussain, Dr. B.B. Kakoti \\ Department of Pharmaceutical Sciences, Dibrugarh University, Dibrugarh, India \\ *Corresponding Author's E-mail: nhussain116@gmail.com
}

Received 08 Dec 2012; Review Completed 12 Jan 2013; Accepted 12 Jan 2013, Available online 15 Jan 2013

\begin{abstract}
Cordia dichotoma is a tree of tropical and subtropical regions.It grows in sub-Himalayan tract and outer ranges, ascending up to about 1500 m elevation. Native: India, Nepal. As a qualitative assay, for the presence of the plant phytoconstituents such as carbohydrates, alkaloids, glycosides,flavonoids, tannins and saponins. Various parts of this plant such as leaves,root as, seed, bark and fruit, possess immunomodulator, antidiabetic, anthelmintic, antiulcer and as a,antilarvicidal and hepatoprotective activities. Various phytopharmacological evaluations have been reported in this literature for the important potential of the Cordia dichotoma.

Keywords: Cordia Dichotoma, Phytochemicals, Pharmacological properties
\end{abstract}

\section{INTRODUCTION}

HISTORY: Cordia dichotoma is a plant species in the genus Cordia. It is called gunda or tenti in Hindi and lasura in Nepali. The fruit of the Fragrant Manjack is called phoa-po-chi in Taiwan where they are eaten pickled. In Burma, the pa-o people are growing the tree (called "thanpet") for its edible leaves. It is a tree about 15 metres high, found spanning from north India and south China to Australia and Polynesia. ${ }^{1}$ It grows wild in the northern part of peninsular Malaysia but is planted in south. Various Synonyms are Cordia myxa Forsk, Cordia oblique Wild, Cordia myxa Roxb etc and Common name are Bhokar, Shleshmantaka etc.

\section{CLASSIFICATION:}

Kingdom: Plantae

Division: Magnoliophyta

Class: Dicotyledons

Subclass: Astaridae

Order: Lamiales

Family: Boraginaceae

Genus: Cordia

Species: Cordia dichotoma Forst.

Fragrant: Manjack

Veracular name:

$\begin{array}{ll}\text { Malaysia } & \text { : Sekendal, sekendai, petekat } \\ \text { English } & \text { : Sebestan plum, soap berry, fragrant } \\ & \text { manjack } \\ \text { India } & : \text { Gonda, lasora, leshora } \\ \text { Javanese } & \text { : Kendal } \\ \text { Sumatran } & \text { : Nunang } \\ \text { Thailand } & \text { : Paw man }\end{array}$

\section{Distribution:}

Cordia dichotoma is a tree of tropical and subtropical regions. It grows in the sub-Himalayan tract and outer ranges, ascending up to about $1500 \mathrm{~m}$ elevation. It is found in a variety of forests ranging from the dry deciduous forest of Rajasthan to the moist deciduous forests of western Ghats and tidal forests in Mayanmar. In Maharashtra, it grows in the moist monsoon forest also.

\section{Local Names:}

Bangali ( buhal, bahubara )

English (sebesten, clammy cherry,Indian cherry)

Gujarati (vadgundo, gunda)

Hindi (lasura, bhokar, borla)

Javanese (Kendal)

Lao (sino-Tibetan) (man, man khok)

Malay (petekat,sekendai)

Tamil (vidi, naruli, kalvirusu)

Nepali (kalo bohori, bohori)

Thai (mandong, manma, phakmong)

Sanskrit (bahuvarka, shleshmatak, shelu)

Botanical description: Cordia dichotoma family Boraginaceae small to moderate-sized deciduous tree with a short bole, short crooked trunk and spreading crown. The stem bark is grayish brown smooth or longitudinally wrinkled. Leaves simple, entire and slightly dentate, elliptical-lanceolate to broad ovate with a round and cordate base. These flowers are followed by 1 in $(25 \mathrm{~mm})$ long dull pinkish edible fruits with sticky flesh flowers are short stalked, bisexual and white in colour, appear in loose corymbose cymes. ${ }^{2}$ 
The fruit is a yellow or pinkish-yellowshining globose or ovoid drupe seated in a saucer-like enlarged calyx. It turns black on ripening and the pulp gets viscid. The hard stone is 1-4 seeded. The generic name honours a $16^{\text {th }}$ century botanist, Valerius Cordus ${ }^{3}$. The specific epithet means having divisions always in pairs.

Phytochemicals: Qualitative assay, for the presence of plant phytoconstituents such as carbohydrates, alkaloids, glycosides, flavonoids, tannins and saponins ${ }^{4}$. Chemicals screening of both the leaves and the fruits showed the presence of pyrrolizidine alkaloids, coumarins, flavonoids, saponins, terpenes and sterols ${ }^{5}$. The fruit contains about $70 \%$ pulp, the pulp contains per $100 \mathrm{~g}$ : water $6 \mathrm{~g}$, proteins $35 \mathrm{~g}$, fat $37 \mathrm{~g}$, and carbohydrate $18 \mathrm{~g}$. The seed contains per $100 \mathrm{~g}$ : water $32 \mathrm{~g}$, fat $46 \mathrm{~g}$, the principal fatty acids are: palmitic acid, stearic acid, arachidic acid, behenic acid, oleic acid and linoleic acid ${ }^{6}$. The petroleum ether and alcoholic extracts showed significant analgesic, antiinflammatory and anti-arthritic activities in tests with rats. Four flavonoid glycosides (robinin, rutin(rutoside), datiscoside and hesperidin), a flavonoid aglycone (dihydrorobinetin), and 2 phenolic derivatives ( chlorogenic acid and caffeic acid) were isolated ${ }^{7}$. The ethanol extract of the leaves reduced acetylcholine-induced contractions of guinea-pig ileum. Ethanol extracts from fruits and leaves showed significant antioxidant activities due to the carotenoids but no antimicrobial activity against gram-positive or gram-negative bacteria. Seeds of the species are anti-inflammatory, 2 compounds alpha-amyrin and 5-dirhamnoside have been isolated ${ }^{8}$.

The bark is medicinal and several chemicals have been identified, Allantoin, $\beta$-sitosterol and 3',5-dihydroxy-4'methoxy flavanone-7-0- alpha-L-rhamnopyranoside 9 . Cordia dichotoma seeds have disclosed the presence of alpha-amyrins, betulin, octacosanol, lupeol-3-rhamnoside, beta-sitosterol, beta-sitosterol-3-glucoside, hentricontanol, hentricontane, taxifolin-3-5-dirhamnoside and hesperitin7 -rhamnoside. The seed contains $\alpha$-amyrin and toxifolin 3,5, dirhamnoside, which shows significant antiinflammatory activity by an oral dose of $1 \mathrm{gm} / \mathrm{kg}$ in albino rats. The seeds of this plant reported to contain fatty acids and flavonoids ${ }^{10}$. The chemical compounds: robinin, rutin, datiscoside, hesperidin, dehydro-robinetin, chlorogenic acid and caffeic acid isolated from Cordia francisci, $C$. myxa and $C$. serratifolia. The leaves contain $12-15 \%$ crude protein, 16-27\% crude fibres, $42-53 \%$ nitrogen free extract, $2-3 \%$ ether extract, $13-17 \%$ total ash, $2-4 \%$ total calcium and about $0.3 \%$ phosphorus.

Traditional used: The bark decoction is used to treat dyspepsia. The powdered bark is applied to mouth ulcers. The bark is also used to treat fever, abscesses and tumors. It is mixed with the pomegranate rind to treat dysentery. The extract of the bark mixed with thecoconut water relieves severe colic. The mucilage of the fruit treats coughs and chest complaints. It is also used to treat uterus and urethra disorders. The kernel of the fruits in the powder form is mixed with oil to heal tinea. The plant is also a diuretic and a laxative ${ }^{11}$

\section{PHARMACOLOGICAL PROPERTIES}

Acute toxicity study: This study was designed to elucidate the toxicity of the widely used plant Cordia dichotoma in rats ${ }^{12}$. The methanolic, chloroform, aqueous extracts isolated from the leaves of Cordia dichotoma and studied their toxic effects. Acute toxicity and $\mathrm{LD}_{50}$ values were determined in experimental rats. The dead animals were obtained from primary screening studies, $\mathrm{LD}_{50}$ value determination experiments and acute studies subjected to postmortem studies. The external appearance of the dead animals, the appearance of the viscera, heart, lungs, stomach, intestine, liver, kidney, spleen and brain were carefully noted and any apparent and significant features or differences from the norm were recorded. Following the chronic administration of the Cordia dichotoma for 14 days, the vital organs such as heart,liver, kidney, testis, spleen and brain were carefully evaluated by histopathological studies and any apparent and significant changes or differences from the norm were studied. Fromthe acute administration of Cordia dichotoma the $\mathrm{LD}_{50}$ values were determined using graphical method. The heart stopped in systolic stand-still in the acute experiments. There were no remarkable changes noticed in the histopathological studies after $50 \mathrm{mg} / \mathrm{kg}$ body weight of the extracts of Cordia dichotoma, when administered intraperitoneally for 14 days successively. Pathologically, neither gross abnormalities nor histopathological changes were observed. After calculation of $\mathrm{LD}_{50}$ values using graphical methods, we found broad therapeutic window and a high therapeutic index value for the Cordia dichotoma extracts. Collectively, these data demonstrate that the extracts of the leaves of the Cordia dichotoma have a high margin of drug safety.

Antiulcer activity: The antiulcer effect of the extract of Cordia dichotoma Forst. Fruits (300 mg/kg body weight) was studied in albino rat of Wistar strain using three different models i.e pyloric ligation, aspirin and indomethacin induced ulcers ${ }^{13}$. The extractions of Cordia dichotoma fruits were carried out using ethanol. The extract was fractionated using petroleum ether, solvent ether, ethyl acetate, butanol and butanone in succession. The Gastric mucosal injury was produced in rats by pyloric ligation, aspirin and indomethacin induced models. Extracts of petroleum ether, solvent ether, ethyl acetate, butanol and butanone were administered in a dose of 300 $\mathrm{mg} / \mathrm{kg}$ body weight. The parameters taken to assess antiulcer activity were volume of gastric secretion, free acidity, total acidity and ulcer index. The results indicates that, extracts of ethyl acetate, butane and butanone i.e significantly $(p<0.001)$ decrease the volume of gastric secretion, free acidity, total acidity and ulcer index with respect to control. The results suggest that the extracts of Cordia dichotomy Forst.f. fruits possess significant antiulcer activity.

Hepatoprotective activity: Study of the methanolic extract of Cordia dichotoma studied its hepatoprotective action in male Wistar rats with carbon tetrachloride induced heart damage (14). Protective role of Cordia myxa L. (CM) against liver fibrosis induced by the carbon tetrachloride $(\mathrm{CCl} 4)$ or thioacetamide (TA) was investigated. Plant was extracted in different solvents and the extracts were evaluated for their phenolic content and anti- oxidant activity. Phenolic content was measured using Folin-Ciocalteu reagent and was calculated as gallic acid equivalents. Antiradical activity of C.myxa extracts was measured by $\alpha, \alpha$-diphenyl- $\beta$-picrylhydrazyl (DPPH) assay and was compared to ascorbic acid. One milligram 
of the crude extract was found to be equivalent to $15 \mu \mathrm{g}$ of ascorbic acid. Protective role of $C$. myxa against carbon tetrachloride or thioacetamide induced fibrosis was assessed in serum aspartate3 transaminase (AST), transaminase (ALT) and alkaline phosphatase (ALP). Level of these enzymes significantly improved in rats after administration of $(\mathrm{CCl} 4)+\mathrm{CM}$, or $(\mathrm{TA})+\mathrm{CM}$ as compared to rats that were treated alone with $\mathrm{CCl} 4$ or TA. It was found that the fresh C.myxa extract offered better protection against liver fibrosis induced by these chemicals.

Wound Healing activity: Study of fruit extracts of $C$ dichotoma showed significant wound healing activity on three different models, viz. excision, incision and dead space wound models on albino rats ${ }^{15}$.The extraction of fruits of Cordia dichotoma Forst.F.was carried out using ethanol. This extract was further fractionated using petroleum ether (40-60\%), solvent ether, ethyl acetate, butanol and butanone in succession. These fractions were screened for wound healing activity using three different models, viz. excision, incision and dead space wound models on either sex of albino rats of Wister strain.All the fractions showed significant $\quad(\mathrm{P}<0.001)$ activity on the fruits contain large quantities of amino acid, flavonoids, and saponins and are used as wound healing agent in households.

Anti-Inflammatory activity: Screening showed the ethanol extract and aqueous fraction of C.dichotoma possess acute anti-inflammatory activity 4 . The effects of Cordia dichotoma Forst. seeds extracts on different phases of acute inflammation were examined. Investigations were performed using different phlogistic agents induced paw edema viz., carrageenan -induced paw oedema and Dextran -induced paw oedema in rats. Various extractas (ethanol and aqueous) of Cordia dichotoma Forst seeds at a dose of $250 \mathrm{mg} / \mathrm{kg}$ and $500 \mathrm{mg} / \mathrm{kg}$ orally were tested. Diclofenac sodium at the dose of $10 \mathrm{mg} / \mathrm{kg}$ was used as a standard. Both the extracts showed significant activity ( $* \mathrm{p}<0.05 \& * * \mathrm{p}<0.01$ ) compared with the control in both of these model. The dry powdered seeds were found to contain alkaloids, glycosides, saponins, tannins and carbohydrates. Thus it is revealed from the screening model used that the ethanol extract and aqueous fraction of this plant possesses acute anti-inflammatory activity ${ }^{10}$.

Antidiabetic activity: Antihyperglycemic effects of Cordia dichotoma Forst in the glucose induced hyperglycemia(1). The effect of the aqueous extract of alloxan induced and normoglycemic Wistar rats has been investigated. Three doses of the extract $(250 \mathrm{mg} / \mathrm{kg} ; 500$ $\mathrm{mg} / \mathrm{kg}$ and $1000 \mathrm{mg} / \mathrm{kg}$ ) wereadministered orally. The 500 $\mathrm{mg} / \mathrm{kg}$ extract of Cordia dichotoma did not show any significant change in the blood glucose levels in normoglycemic and $250 \mathrm{mg} / \mathrm{kg}$ did not show any significant change in the blood glucose levels in alloxan induced Diabetic Wistar rats, when compared to untreated control. The dose $500 \& 1000 \mathrm{mg} / \mathrm{kg}$ of extract showed a significant $(\mathrm{p}<0.5)$ decrease in blood glucose levels after 4 ,
8 , and 24 hours. In normoglycemic rats, the dose of 1000 $\mathrm{mg} / \mathrm{kg}$ of the extract significantly $(\mathrm{p}<0.05)$ decrease the blood glucoselevels at 8 and 24 hours. In conclusion, The doses of extract has shown both significant $(p<0.05)$ hypoglycemic and antihyperglycemic effects in Wistar rats 16 .

Degenerative disorders: Role of Cordia dichotoma seeds and leaves extract in degenerative disorders ${ }^{2}$. A common theme which underlies etiology of several degenerative disorders is free radical induced stress. free radicals prime the immunomodulatory response, recruit inflammatory cells and are innately bactericidal. in the body, excess production of free radicals affect lipid cell membranes to produce lipid peroxides and reactive oxygen species (ROS), Which leads to decline in membrane fluidity and many biological changes, such as DNA damage, ageing, heart disease and cancer etc.

Antioxidants serve as free radical scavengers neutralizing and defending the body from a number of diseases which are born because of generation of free radicals. They offer defense against radical toxicity by antagonizing the damages caused by free radicals.

The current study is therefore carried out to investigate the free radical scavenging potential of methanolic extract of seeds and leaves of Cordia dichotoma using in-vitro models viz. DPPH and hydrogen peroxide model. These models demonstrate positive antioxidant activity in a concentration dependant manner and demonstrate that highest concentration exhibits highest $(100 \mu \mathrm{g} / \mathrm{ml})$ antioxidant activity. This activity was more pronounced in leaves as compared to seeds.

Antimicrobial activity: Consequently, data pertaining only to that showed inhibitory activities against all the tested bacterial, fungal and yeast species. Extracts of Cordia dichotoma showed moderate activity against the tested organisms. Water extracts of the Cordia dichotoma plants did not show any antimicrobial activity against all the tested microorganisms ${ }^{17}$.

Miscellaneous activity: A method of treating a human body for delaying effects of ageing on skin thereof, by applying to a part of the skin in need thereof of a cosmetic or pharmaceutical composition containing an amount of an extract of Cordia dichotoma effective to inhibit activity of elastase in the skin, obtaining thereby the delaying of the effects of ageing on the skin and also some extend Larvecidal activity. ${ }^{18}$

\section{CONCLUSION}

Numerous phytochemical and pharmacological studies have been conducted on different parts of the Cordia dichotoma. The present literature supports the potential of the Cordia dichotoma as a medicinal tree. In view of the nature of the plant, more research can be done to investigate the unexplored and unexloited potential of this plant.

\section{REFERENCES}

1.Kirtikar KR,BasuBD,Indian Medicinal Plants, Edition 11, Vol 3, Orient enterprises, 1935,1029-1030.

2. Sharma A, Bhardwaj S, Mann AS, Jain A, Kharya MD, Screening Methods of Antoxidant Activity :An Overview, Phcog Rev,Issue 2, JulDec2007, 232-238.

3 .Ilhami GO et al, Journal of Ethnopharmacology,90, 2004,205-215. 
4. Parmar NS and Shikha parmar.,,Anti-ulcer poterital of flavonoids,Indian J. Physiol.Pharmacol., 1998,48,343-351.

5., D.L., Martin Alarcon, M.J.and Motilva, V.J. Ethnopharmacol., 1994,42,161-170.

6. Srivastava SK, Srivastava SD, Taxifollin 3,5-dirhamnoside from the seeds of Cordia dichotoma, Phytochemistry, Volume 18,1979, 205-208.

7. Yang., Fu, P,P.,Y.C., Xia, Q., Chou, M.C.,Cui, Y.Y.,Lin G., “Pyrrolizidine alkaloids-tumorigenic components in Chinese herbal medicines and dietary supplements", Journal of Food and Drug Analysis, Vol. 10, No. 4,2002,198-211.

8 .Larson RA, The antioxidants of higher plants, phytochem. 27, 1998, 969-78.

9. Tiwari KP and Srivastava SSD.1979. Chemical investigation of the stem bark of Cordia oblique, Planta Medica. 36(2): 191-192.

10. Al-Awadi FM, Srikumar TS, Anim JT and Khan I. Antiinflammatory Effects of Cordia myxa Fruit on Experimentally Induced Colitis in Rats. Nutrition. 2001;17(5):391-396.

11. Ficarra R, Ficarra P, Tommasini S, Calabro ML, Ragusa S, Barbera R \& Rapisarda A., Leaf extracts of some Cordia species: Analgesic and Antiinflammatory activities as well as their chromatographic analysis. Farmaco.,1995, 50(4): 245-256.

13. Wassel G, El-Menshaw B, Saud A, Meharuna G. and El-Merzabani M., Screening of selected plant for Pyrrolizidine alkaloids and antitumor activity, Pharmazine, 1987, 42,709.

14. Thirupathi K, Sathesh Kumar S, Govardhan P, Ravikumar B, Krishna D, Krishna G Mohan/Nigerian, Hepatoprotective action of Cordia dichotoma against carbon Tetrachloride induced heart injury in Rats. Journal of Natural Products and Medicine.2007, vol.11.

15. Kuppasta IJ,Nayak PV., Wound healing activity of Cordia dichotoma Forst. fruits. Natural Products Radiance. 2006,5: 99-102.

16. Day C. Traditional plants treatments for diabetes mellitus: Pharmaceutical Foods.,Brit. J. Nutr. 1998,80: 5-6.

17. Kuppasta IJ. \& Nayak PV. Anthelmintic activity of fruits of Cordia dichotoma. Ind. J. Nat.Prod. 2003, 19(3):27-29.

18. Anjana K. Patel, Nimish pathak, Hardik Trivedi, Mahendra G, Mihir P, Nitin P. Phytopharmacological properties of Cordia dichotoma as a Potential Medicinal Tree: an overview. Int. J. of Institutional Pharmacy and Life Sciences.,2011,1(1): 40-51. 